\title{
Thermo gravimetric Investigations of Mixed Metal Tartrates leading to Oxidic Spinels
}

\author{
P. S.Shah ${ }^{1}$,F.V. Dandawate ${ }^{2}$ \\ ${ }^{1,2}$ Dept.of Chemistry, Dr. D. Y. Patil Arts, Commerce and Science College , \\ Pimpri, Pune, M.S. India.
}

\begin{abstract}
The present investigationconsistsof study of the thermal decompositions of mixed metal tartrates obtained by co-precipitation method forming cobaltites as final products. The solutions of $\mathrm{M}_{2} \mathrm{SO}_{4}$ $(\mathrm{M}=\mathrm{Cd}, \mathrm{Ni}, \mathrm{Cu})$ and cobalt sulphate, heptahydrate are used. The mixed tartrates of $\mathrm{Cd}-\mathrm{Co}, \mathrm{NI}-\mathrm{Co}$ and $\mathrm{Cu}-$ Co are synthesized by the addition of $10 \%$ disodium tartrate. These tartrate compounds are characterized by the elemental analysis, metal analysis and infrared spectra. They are decomposed thermally and decomposition reactions are recorded on Sieko instrument under static air atmosphere. In these tartrate compounds, the dehydration takes place in a single stage within the temperature range of 35$210^{\circ} \mathrm{C}$. The DTG and DTA curves of these tartrate compounds show the broad exothermic peaks. Further the decompositions of intermediate carbonate compounds are observed within the temperature range of $410-600^{\circ} \mathrm{C}$ leading to corresponding cobaltites. The cobaltites, thus obtained,are characterized by the chemical analysis, infrared spectra and powdered XRD techniques.
\end{abstract}

\section{Keywords}

Mixed Metal Tartrates, Thermo gravimetric Analysis, Cadmium cobaltite, Nickel cobaltite, and Coppercobaltite.

\section{Introduction}

The cobaltites of zinc, nickel, and copper were synthesized for the first time by Holgerson and Karlsson by using metal nitrate solutions. Binary metal cobaltites $(\mathrm{M}=\mathrm{Ni}, \mathrm{Zn}, \mathrm{Cu})$ were synthesized by thermal treatment of mixed hydroxides [1, 2] and alsoby usingoxalates [3], hydroxide nitrates [4] malonatehydrazines[5],hydroxycarbonates[6], hydrazinium compounds [7]hydrazine carboxylates [8] hydrothermal and precipitation method.[9] The synthesis of various types of cobaltites were reported by many scientists[10, 11, 12]. From the literature survey, it is apparent that inspite of its long history, the studies on these compounds are still presenting useful information. The present investigation has been undertaken to study the thermal decompositions of tartrates of $\mathrm{Cd}-\mathrm{Co}$, Ni-Co, and $\mathrm{Cu}-\mathrm{Co}$ leading to corresponding cobaltites.

\section{Materials and Methods}

A solution of mixture of Cadmium sulphate, octahydrate and cobalt sulphate, heptahyrate was used .Disodium tartrate (10\%) was added with constant stirring till a permanent precipitate occured. Equal amount of distilled acetone was added to get homogenous co-precipitate. The light pink precipitate of Cadium-cobalt tartarate $\left[\mathrm{CdCo}_{2}\left(\mathrm{C}_{4} \mathrm{H}_{4} \mathrm{O}_{6}\right)_{3} 0.5 \mathrm{H}_{2} \mathrm{O}\right.$ ]was filtered, washed with distilled water and airdried at ambient temperature. Similarly,Nickel-cobalt tartrate $\left[\mathrm{NiCo}_{2}\left(\mathrm{C}_{4} \mathrm{H}_{4} \mathrm{O}_{6}\right)_{3} \cdot \mathrm{H}_{2} \mathrm{O}\right]$ and Copper-cobalt tartrate $\left[\mathrm{CuCo}_{2}\left(\mathrm{C}_{4} \mathrm{H}_{4} \mathrm{O}_{6}\right)_{3} \cdot \mathrm{H}_{2} \mathrm{O}\right]$ were prepared by using Nickel sulphate, hexahydrate and copper sulphate, pentahydrate respectively. 
The elemental analyses of carbon and hydrogen for all three tartrate compounds were done by micro analytical technique, The metal analyses of these tartrate compounds were carried out by using the Perlein Elmer Model 3110 Atomic Absorption Spectrophotometer (AAS) employing an air acetylene flame and a hollow cathode lamp as the light source. The infrared spectra of these tartrate compounds were recorded in the region of $4000-400 \mathrm{~cm}^{-1}$ on the Perkin-Elmer 783 spectrophotometer using nujol mull . Thermal decompositions of tartrate compounds of each sample were recorded on Sieko instruments under static air atmosphere with $5 \mathrm{mg}$ sample weight using platinum crucible at the temperature range of $30-700^{\circ} \mathrm{C}$ with the heating rate of $10^{\circ} \mathrm{C}$. The $\mathrm{x}$-ray diffraction patterns were determined on Rigaku miniflex diffractometer using $\mathrm{CuK} \alpha$ radiatio $(\lambda$ $=1.5405 \mathrm{~A}^{0}$.Nickel filter )

\section{Results\& Discussion}

It is observed from the analytical data of $\left[\mathrm{CdCo}_{2}\left(\mathrm{C}_{4} \mathrm{H}_{4} \mathrm{O}_{6}\right)_{3} 0.5 \mathrm{H}_{2} \mathrm{O}\right],\left[\mathrm{NiCo}_{2}\left(\mathrm{C}_{4} \mathrm{H}_{4} \mathrm{O}_{6}\right)_{3} \cdot \mathrm{H}_{2} \mathrm{O}\right]$ and $\left[\mathrm{CuCo}_{2}\left(\mathrm{C}_{4} \mathrm{H}_{4} \mathrm{O}_{6}\right)_{3} \quad . \mathrm{H}_{2} \mathrm{O}\right]$ that the elemental analysis made in weight percent for these tartrate compounds are very well matched with calculated values (Table 1). The infrared spectra of tartarate compounds of $\mathrm{Cd}-\mathrm{Co}$, Ni-Co \& $\mathrm{Cu}-\mathrm{Co}$ show a band at $3445 \mathrm{~cm}^{-1}$ corresponding to the weakly bonded water of crystallization and intense band at $1604 \mathrm{~cm}^{-1}$ due to $v_{\text {asym }}(\mathrm{C}=0)$ and bonds at $1452 \mathrm{~cm}^{-1}$ and $1375 \mathrm{~cm}^{-1}$ due $v_{\text {sym }}(C=C)$ and coordinate carboxylate group [13]. In addition to this, strong bands at $1085 \mathrm{~cm}^{-1}$ and $1045 \mathrm{~cm}^{-1}$ indicates the presence of secondry $-\mathrm{OH}$ group tartrate. From these results, it can be suggested that there was no bonding with free -OH group to that metal in solid state [14]. The bidentate linkages of the carboxylate group with the metal was confirmed on the basis of difference between the unsymmetric and symmetric stretching frequencies. Hence these tartarate compounds show a chain-like polymeric octahedral structure [15].

The thermal analysis measurements confirm the presence of water of hydration for these tatrate compounds. The TG, DTG and DTA curves of these tatrate compounds under oxygen atmosphere are shown in Fig.1. The complete data for the observed and calculated mass losses for different stages of decomposition of compounds and the corresponding temperature ranges are shown in (Table 2).

The TG curves showed continuous mass losses between $35-190^{\circ} \mathrm{C}$ in $\mathrm{Cd}-\mathrm{Co}$ tartrate, $35-210^{\circ} \mathrm{C}$ in $\mathrm{Ni}-\mathrm{Co}$ tartrate and $35-240^{\circ} \mathrm{C}$ in $\mathrm{Cu}-\mathrm{Co}$ tartrate, indicating that the anhydrous tartrates formed at these temperatures were unstable. The decompositions of anhydrous tartrates took place in two stages with very strong exothermic peaks on DTA and DTG curves at the same temperatures. The exothermic peaks were attributed to the oxidation of $\mathrm{Co}^{2+}$ to $\mathrm{Co}^{3+}$ by oxygen atmosphere.

The intermediate carbonates in each compounds decomposed between $410^{\circ} \mathrm{C}$ to $600^{\circ} \mathrm{C}$ with the evolution of $\mathrm{CO}_{2}$ forming corresponding cobaltites. The observed mass losses were in good agreement with calculated values. The changes occured in DTA curves are at about $440^{\circ} \mathrm{C}$ in Cd-Co tartrate, $370^{\circ} \mathrm{C}$ in $\mathrm{Ni}-\mathrm{Co}$ tartrate and $360^{\circ} \mathrm{C}$ in $\mathrm{Cu}-\mathrm{Co}$ tartrate. The gaseous products such as Ethylene $\mathrm{CO}_{2}$ and $\mathrm{CO}$ obtained by thermal decompositions of tartrate compounds under oxygen atmosphere were analyzed by qualitative gas detection method. Carbon-dioxide was detected by precipitation as $\mathrm{CaCO}_{3}$ from the solution of $\mathrm{Ca}(\mathrm{OH})_{2}$ while $\mathrm{CO}$ is detected by reduction of iodine-pentoxide to Iodine. Ethylene gas was detected by the decolorization of bromine water ( $2 \% \mathrm{Br}_{2}$ in $\mathrm{CCl}_{4}$ ) or $\mathrm{KMnO}_{4}$ solution.

On the basis of TG. DTG and DTA studies, the following tentative scheme is proposed for the thermal decomposition of tartrate compounds in oxygen atmosphere.

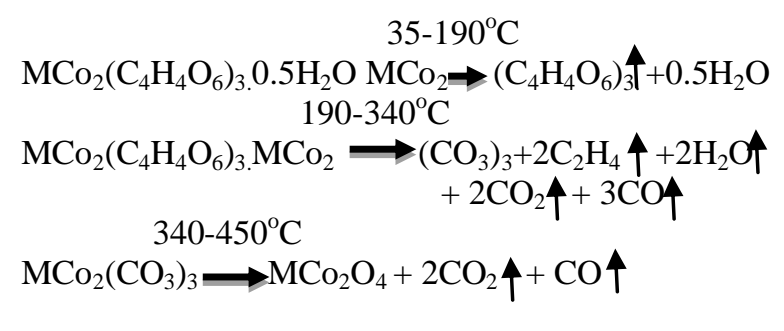

Where $\mathrm{M}=\mathrm{Cd}, \mathrm{Ni}, \mathrm{Cu}$ 
Thus, the mixed metal tartrates on thermal decomposition formed respective cobaltites as the final products. The formation of $\mathrm{CdCo} 2 \mathrm{O} 4, \mathrm{NiCo}_{2} \mathrm{O}_{4}$ and $\mathrm{CuCo}_{2} \mathrm{O}_{4}$ were confirmed by the chemical analysis, infrared spectra and X-ray diffraction studies. The experimentally observed d-spacing
ISSN 2455-6378

values and relative intensities of these cobaltites formed are shown in Table 3and were found to be well- matched with those reported in literature [16, 17, 18 ]. This clearly revealed the formation of desired cobaltites [19].

Table 1 : Analytical data of Cd-Co and Ni-Co Tartarate precursors.

\begin{tabular}{|c|c|c|c|c|c|c|c|c|c|c|c|c|c|}
\hline \multirow{3}{*}{$\begin{array}{c}\text { Tartrate } \\
\text { Compounds }\end{array}$} & \multirow{3}{*}{$\begin{array}{l}\text { Formula } \\
\text { Weight }\end{array}$} & \multicolumn{12}{|c|}{ Elemental analysis in wt $\%+0.5$} \\
\hline & & \multicolumn{2}{|c|}{$\mathrm{C}$} & \multicolumn{2}{|c|}{$\mathrm{H}$} & \multicolumn{2}{|c|}{$\mathrm{Co}$} & \multicolumn{2}{|c|}{$\mathrm{Cd}$} & \multicolumn{2}{|c|}{$\mathrm{Ni}$} & \multicolumn{2}{|c|}{$\mathrm{Cu}$} \\
\hline & & Cald & Obsd & Cald & Obsd & Cald & Obsd & Cald & Obsd & Cald & Obsd & Cald & Obsd \\
\hline $\begin{array}{l}\mathrm{CdCo}_{2}\left(\mathrm{C}_{4} \mathrm{H}_{4} \mathrm{O}_{6}\right)_{3} . \\
0.5 \mathrm{H}_{2} \mathrm{O}\end{array}$ & 683.27 & 21.07 & 21.49 & 1.90 & 2.34 & 16.18 & 16.69 & 15.40 & 14.98 & & & --- & ---- \\
\hline $\begin{array}{l}\mathrm{NicO}_{2}\left(\mathrm{C}_{4} \mathrm{H}_{4} \mathrm{O}_{6}\right)_{3} . \\
\mathrm{H}_{2} \mathrm{O}\end{array}$ & 638.58 & 22.55 & 22.16 & 2.19 & 2.33 & 17.00 & 17.50 & --- & --- & 8.47 & 9.51 & & \\
\hline $\begin{array}{l}\mathrm{CuCo}_{2}\left(\mathrm{C}_{4} \mathrm{H}_{4} \mathrm{O}_{6}\right)_{3} . \\
\mathrm{H}_{2} \mathrm{O}\end{array}$ & 643.41 & 22.38 & 21.67 & 2.02 & 1.96 & 17.81 & 16.77 & -- & -- & & & 9.60 & 9.12 \\
\hline
\end{tabular}

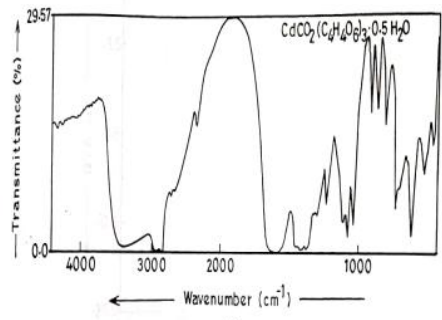

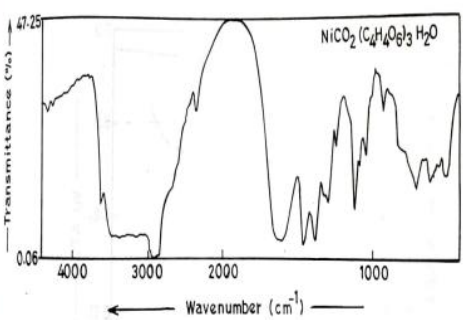

(b)

FIg. 1 ; Infrared spectra of (a) Cd- Co tartrate (b) Ni- Co tartrate (c) Cu- Co tartrate

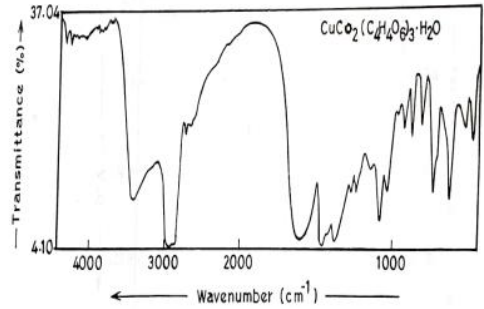

(c)

Table 2: TG-DTG-DTA data of tartrates of $\mathrm{Cd}-\mathrm{Co}$, Ni-Co and $\mathrm{Cu}-\mathrm{Co}$ under Oxygen atmosphere.

\begin{tabular}{|c|c|c|c|c|c|}
\hline \multirow{3}{*}{ Compounds } & \multicolumn{3}{|c|}{ TGA } & \multirow{3}{*}{$\begin{array}{l}\text { DTG Peak } \\
\text { Temp } .\left({ }^{\circ} \mathrm{C}\right)\end{array}$} & \multirow{3}{*}{$\begin{array}{c}\text { DTA } \\
\text { Peak } \\
\text { Temp } .\left({ }^{\mathrm{O}} \mathrm{C}\right)\end{array}$} \\
\hline & \multicolumn{2}{|c|}{$\%$ mass loss } & \multirow{2}{*}{$\begin{array}{c}\text { Temp range } \\
\left({ }^{\circ} \mathrm{C}\right)\end{array}$} & & \\
\hline & Obsd. & Cald. & & & \\
\hline Cadmium-cobalt & 1.79 & 1.32 & $35-190$ & 155 & 170 \\
\hline Tartrate, half & 41.81 & 42.12 & $190-340$ & 320 & 315 \\
\hline $\mathrm{CdCo}_{2}\left(\mathrm{C}_{4} \mathrm{H}_{4} \mathrm{O}_{6}\right)_{3}, 0.5 \mathrm{H}_{2} \mathrm{O}$ & 25.29 & 24.60 & $340-450$ & 380 & 400 \\
\hline Nickel- cobalt & 2.91 & 2.82 & $35-210$ & 170 & 190 \\
\hline Tartrate, monohydrate & 36.81 & 37.18 & $210-320$ & 341 & 345 \\
\hline $\mathrm{Ni} \mathrm{Co}_{2}\left(\mathrm{C}_{4} \mathrm{H}_{4} \mathrm{O}_{6}\right)_{3} \mathrm{H}_{2} \mathrm{O}$ & 39.03 & 38.28 & $320-334$ & 400 & 420 \\
\hline Copper-cobalt & 1.79 & 1.55 & $35-240$ & 165 & 180 \\
\hline Tartrate,monohydrate & 46.23 & 45.41 & $240-360$ & 318 & 320 \\
\hline $\mathrm{CuCo}_{2}\left(\mathrm{C}_{4} \mathrm{H}_{4} \mathrm{O}_{6}\right)_{3} \mathrm{H}_{2} \mathrm{O}$ & 29.02 & 28.12 & $360-460$ & 385 & 390 \\
\hline
\end{tabular}


Table 3 : XRD Data of Cobaltites of $\mathrm{Cd}, \mathrm{Ni}$ and $\mathrm{Cu}$

\begin{tabular}{|c|c|c|c|c|c|c|}
\hline \multirow{2}{*}{ hkl } & \multicolumn{2}{|c|}{$\mathrm{CdCo}_{2} \mathrm{O}_{4}$} & \multicolumn{2}{|c|}{$\mathrm{NiCo}_{2} \mathrm{O}_{4}$} & \multicolumn{2}{|c|}{$\mathrm{CuCo}_{2} \mathrm{O}_{4}$} \\
\hline & Reported $^{16}$ & Obsd. & Reported $^{17}$ & Obsd. & Reported $^{18}$ & Obsd. \\
\hline 111 & $4.667(10)^{\mathrm{a}}$ & $4.668(15)$ & $4.690(14)^{\mathrm{a}}$ & $4.669(16)$ & $4.460(10)$ & $4.691(13)$ \\
\hline 220 & $2.863(35)$ & $2.873(23)$ & $2.869(25)$ & $2.838(33)$ & $2.855(30)$ & $2.873(33)$ \\
\hline 311 & $2.440(100)$ & $2.447(100)$ & $2.447(100)$ & $2.440(100)$ & $2.434(100)$ & $2.447(100)$ \\
\hline 222 & $2.337(09)$ & $2.354(07)$ & $2.342(10)$ & $2.378(11)$ & $2.331(10)$ & $2.336(33)$ \\
\hline 400 & $2.024(18)$ & $2.030(15)$ & $2.029(25)$ & $2.021(22)$ & $2.018(20)$ & $2.027(26)$ \\
\hline 331 & $1.858(01)$ & $1.850(05)$ & $1.656(08)$ & $1.660(11)$ & $1.848(15)$ & $1.840(20)$ \\
\hline 422 & $1.652(12)$ & $1.663(16)$ & $1.562(30)$ & $1.552(27)$ & $1.648(10)$ & $1.640(03)$ \\
\hline 511 & $1.558(35)$ & $1.550(30)$ & $1.434(45)$ & $1.439(41)$ & $1.554(35)$ & $1.559(30)$ \\
\hline
\end{tabular}

Note :- The figures in parentheses are intensities to the linewidth intensity (100).

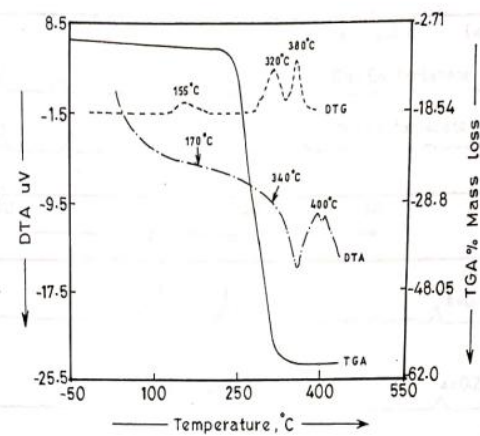

(a)

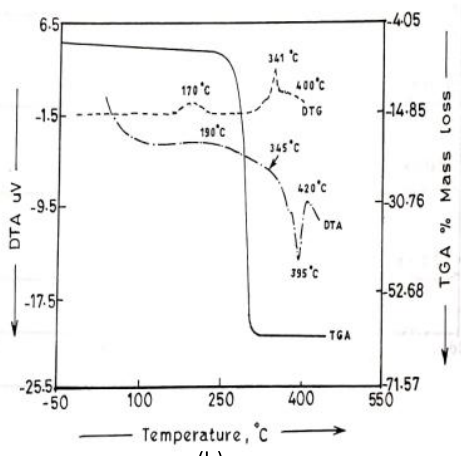

(b)

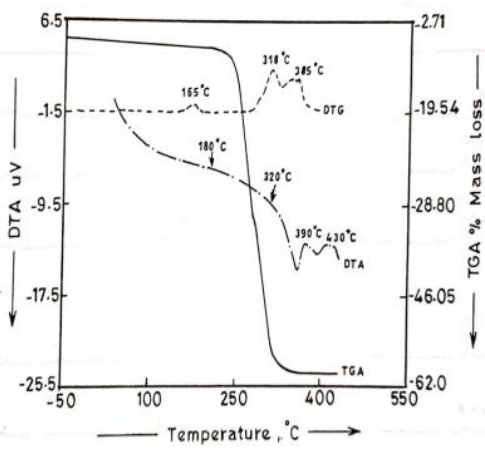

Fig. 2 ; TGA, DTG, and DTA curves for (a) Cd- Co tartrate (b) Ni- Co tartrate (c) Cu-Co tartrate

\section{Conclusion:-}

The tartarate compounds of $\mathrm{Cd}-\mathrm{Co}$, Ni-Co and $\mathrm{Cu}-\mathrm{Co}$ were prepared by the co-precipitation method. They were characterized by the elemental analysis, metal analysis, infrared spectra. The infrared spectra of these tartrate compounds showed a chain-like polymeric octahedral structure. These tartrate compounds were thermally decomposed and decomposition reactions were studied under static air atmosphere. The dehydration was is found to be in a single stage within the temperature range $35^{\circ}-210^{\circ} \mathrm{C}$ .The broad exothermic peaks were found from DTG and DTA curves. Further, the decomposition of intermediate carbonate compounds were found within the temperature range of $410^{\circ}-600^{\circ} \mathrm{C}$, which finally formed corresponding metal cobaltites. Thus, $\mathrm{CdCo}_{2} \mathrm{O}_{4}, \mathrm{NiCo}_{2} \mathrm{O}_{4}$ and $\mathrm{CuCo}_{2} \mathrm{O}_{4}$ were prepared by the thermal decomposition of corresponding tartrate compounds. The formation of these cobaltites were confirmed from metal analysis, infrared spectra, and powdered XRD. The Cobaltite's are used as catalysts [22], supercapacitors [23], and gas sensors [24].

\section{Acknowledge}

We would like to take an opportunity to thank the Management and Dr. Mohan B. Waman, Principal, Dr. D. Y. Patil Arts Commerce and Science College, Pimpri, Pune-18 for valuable co-operation and constant encouragement 


\section{References}

1] Supriya Singh, Pratibha Srivastava, Inderpal Singh Kapoor, J. Experimental Nanoscience, 10, (1):29-44, (2013)

2] H. Baussart, R. Delobel, M.LeBras and J. M.Leroy, J.Chem. Soc.Faraday Trans. 1 (75): 1337, (1979)

3] P. Peshev, A. Toshev and G. Gyurov, Mat. Res. Bull, 24: 33-35, (1989)

4] D .G .Klissurski and E.L.Uzunova , and K. Ivanov.,Catal.Letters, 15:385-389, (1992)

5] B.N. Sivasankar and S. Govindrajan, Synth. React. Inorg. Met.Org.Chem. 24:1573-1577, (1994)

6] D.G.Klissurski ,E. L. Vzunova,189,(1):143149 (1991)

7] C. Sonia , R. Ragul, B.N. Sivasankar, J. Chem. Pharm. Res. 5(3) 66-72, (2013)

8] S.T.Aruna, K.C.Patil, WileyOnline Library http://doi.org/10.1002/9781118693599.ch02. xml. (Jan,2014)

9] D. Nicheva, V.Boev, P.Petkov,G.Avdeev, T.Petkova, Advanced Nano Technologies for Detection and Defense against CBRN Agents, 79-86 (Jan. 2018)

10] R.Raghul, B N Sivasankar - J. Chem. Crys. 42(6):533-542,(2012)

11] L.R.Raghunath, B N Sivasankar, J.Chem. Crys. 40(12): 1170-1174 (2010)
12] S.Yasodhai,V.Gomathi,B.Vinobha,Coordn. Chem59:1615-1617 (2006)

13] K. Nakamoto, Infrared Spectra of Inorganic and co-ordinated compounds, Wiley Interscience, New York, $6^{\text {th }}$ edition, (2008)

14] V. Frei and J. Ederove, Colect. Czech.Chem.Comm. 34:1304 (1969)

15] J. R. Allan, N. D. Baried and A. L. Kassyk, J. Thermal. Anal.16:79-83 (1979)

16] B.N.Sivsankar and S.Govindrajan, Mat.Res.Bull. 1,(31):29-35(1996)

17] Powder Diffraction file, Inorganic volume, IS-5iRB,Joint Committee on Diffraction Standards, Pennsylvania (1967)

$18]$ N. M. Deraz, Moustafa M. G. Fouda. Int. J. Electrochem Sci. 8:2682-2690, (2013)

19] D. Santosh Shanthakumar, B. N. Sivasankar, A. J. Checm. doi :10.14233/AJCHEM.2014, 16781 (2014)

20] F.C Romejin ,Phillips,Res-Rep.8,304(1953)

21] K.C.Patil,Bull.Mater.Sci.16:533-541 (1993)

22] Supriya Singh, Pratibha Srivastava, Inderpal Singh Kapoor, J. Experimental Nanoscience, 10, (1):29-44, (2013)

23] Neha Garg, Mrinmoyee Basu, Ashok Kumar Ganguli, J.Phy.Chem. (ACS publication), 118(31):17332-17341(2014)

24] Oday A. Hammadi, Noor E. Naji, Photonic Sensors, 8:43-47(2018) 